\title{
A Network Issues Segment with Effective Structure
}

\author{
Kavita Srivastava \\ Faculty of BCA, Department of Business Management \\ And Entrepreneurship, Dr. R. M. L. A. University Ayodhya
}

\begin{abstract}
Computer Network is increasing ubiquitous now a day's computer network is more than that of collection of devices interconnected with one another the computer network are system of computers interconnected for the aim to share data \& information in digital framework the computer network enables for analyzing organizing the information which is good for gaining profitable operations. The waking up and speeding of internet $\&$ intranet is an important aspect of networking of computer both internet \& intranet works accordingly and are important part of computer networking which are based on technology of internet, In present scenario businesses are implementing intranet at each \& every step and only reason is internet which enables the business to collect, manage and disseminate the information more mostly easily and in a sequential manner also in the current scenario of globalization computer is needed at each \& every step. In this research paper we are highlighting basic concept of networking.
\end{abstract}

Index Terms- Computer Network, Network Communication \& Protocol in Network.

\section{INTRODUCTION}

Networking supports the communication among the two or more programs which are running on physically distance machines all the computers collect \& form computer network as such as the computers are connecter that the data can be exchange between one another on computer network [1]. A network is created when two or more then that computer are connected by information sharing and showing of resources, a set of computers used for exchanging information by a same connection called protocol in the media communication $[2,6]$. A computer network is simply the computer wired together in such a way which is helpful in data sharing or the devices such as CD, ROMs, printer faxmodems etc. A computer network is interconnected collection of autonomous computers where the word interconnected means exchange of information from on computer to another, the networks in a computer are inter locked by networking. In the world of globalization and internet networking plays key role for different organization success by creating a network environment and connecting the device. In a normal

\section{NETWORK EVAUATION ENVIRONMENT}

Networking is further classified into two types used networking a networking where computers are interconnected by wireless \& cables a sort of networking without wires or cables [4]. The computer networking has few terms such as NIC or network

\section{PROTOCOL IN NETWORK ENVIRONMENT}

A network protocol explains the regulations for exchange of data or information between network devices the network protocol consist of mechanism for devices for identification \& making connections with sense networking is said to be a process of information exchange among two or more people in an industry which could help in several ways but in technical term network [5]. Is defined a process where two or more group of computer are linked with one another for the exchange of information, as we have various devices for networking which connects a computer to another computer like Router Hub, Switch. Also we have few hardware set required for computer network such as network cables distributor, internal \& external cards etc but the main aspect in computer networking is service \& the protocols where in the services can be given by the providers of services further we see different types of categories such as topology, with star and ring which shows geometrical arrangement of computer system and the protocols for the LAN is called as Ethernet [3]. Which is used for common of data and last one is architectural network in peer to peer \& server model. Hence the hardware \& software combines over networking for common connectivity, management \& operations.

interface card LAN or Local area network, server hub switch \& more.

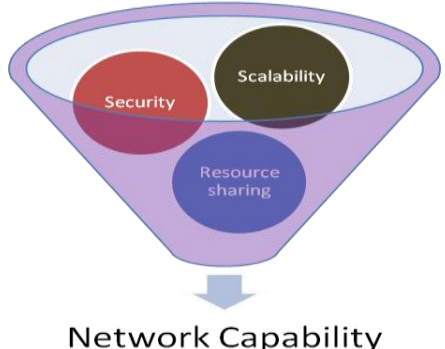

Figure 1 Network Dependency 


\section{Available online at www.ijrat.org}

one another as well as formatting the rules between formatting the rules which specify how data is packed into message received \& sent few protocols also supports messages and data compression is prepared for reliable or high performance network communication the modern protocols for computer networking generally use packet switching technique for sending and receiving messages which are further subdivided into pieces which collect $\&$ reassembled at the desired destination [8]. Thousand of different computer protocol has developed for specific purpose \& the environment. Basic three protocols have captured the overall network of particular system.

\subsection{Internet Protocol}

The internet protocol (IP) family consist a set of related network protocols a part internet protocol itself higher level protocols such as TCP, UDP, HTTP \& FTP integrate with IP to provide additional capabilities.

\subsection{Wireless Network Protocol}

The use of Wi-Fi, Bluetooth and LTE, wireless networks are becoming common place the network

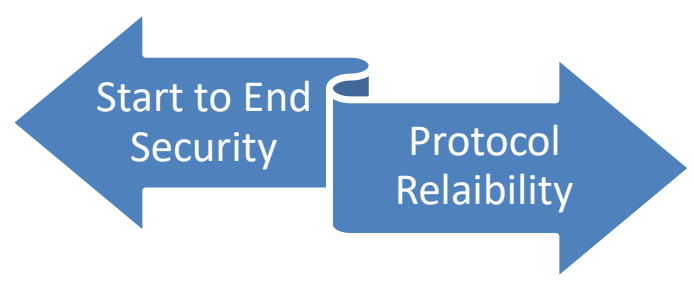

Figure 2 Two Stages for Improvement

\section{CONCLUSION}

In this study about the networking and the support communication between programs the advent technology the age of networking and the computer which are interconnected for digitalization. We also studied about the protocol in the network environment along with the several characteristics of protocols. We have presented the basic improvement and key concepts of networking the support of common the networking facility.

\section{REFERENCES}

[1] Hong Yaling. Research on computer network security analysis model [J]. Computer CD Software and Applications, 2013.

[2] Cui Jing, Liu Guangzhong, the basics of computer network [J]. Tsinghua University Press, 2010.

[3] Xiao Ze. Research on computer network security analysis model $[\mathrm{J}]$. Journal On Communications, 2012. protocols designed for use of wireless network should support roaming mobile devices and dealt with matter of variable rates \& network security.

\subsection{Networking Routing Protocol}

The routing protocols are the specific purpose protocol prepared for use by network routers on the internet. A routing protocol is identified by routers to manage the pathways between the sources and destinations of network messages which make dynamic routing divisions.

\section{NETWORK IMPROVEMENT STAGE}

According to the characteristics of computer network is difficult and complex implementation of a particular system. The complex system has involved the some critical stages as security, domain level, efficiency, data reliability, and its capability [7]. The data and information have shared at various modes when transferring between two phases as end to start. An expert gives the valuable suggestion to the system and presented by thefigure2.
[4] C. R. Berger, S. H. Chaffee, "The study of communication as a science", Handbook of Communication Science, 1989.

[5] B. Endicott.Active Defense to Cyber Attacks. Information Assurance and Security [J].2014.

[6] Zhao Ran, Wang Qunyong. Henan Science and Technology, Vol. 1 (2014) No 27, p.74-76.

[7] A. Mishra, D. Agarwal and M. H. Khan, "Availability Estimation Model: Fault Perspective", International Journal of Innovative Research in Science, Engineering and Technology, Vol. 6, Issue 6, June 2017.

[8] Kavita Srivastava, "A Study Of Network Security with New Technology", American International Journal of Research in Science, Technology, Engineering \& Mathematics, Volume 1, Issue 25, December 2018 to February 2019. 